\title{
Modelagem Plana Industrial do Vestuário: diretrizes para a indústria do vestuário e o ensino-aprendizado
}

\author{
Theoretical guidelines for the teaching of Modeling flat industrial clothing: from the point of \\ view of industry and teaching and learning
}

\author{
MENEZES, Marizilda dos Santos \\ Doutora; Universidade Estadual Paulista - FAAC \\ marizil@faac.unesp.br
}

SPAINE, Patrícia Aparecida de Almeida

Mestre; Faculdade do Norte Pioneiro

patricia.almeida.82@gmail.com

\begin{abstract}
Resumo
O trabalho apresenta a importância do processo de modelagem plana industrial no campo do design de moda. Para tanto realizou uma pesquisa qualitativa identificando a visão de modelistas, alunos e docentes a cerca dessa etapa de elaboração e produção do produto do vestuário no pólo regional de Londrina - PR. Esta pesquisa possibilitou o desenvolvimento das diretrizes metodológicas para o processo de ensino e elaboração da Modelagem Plana Industrial do vestuário.
\end{abstract}

Palavras Chave: Design de moda; Processo produtivo; Modelagem Plana Industrial; Diretrizes metodológicas.

\begin{abstract}
The work shows the importance of process modeling in industrial flat field fashion design. This was achieved by a qualitative study identifying vision of modelers, students and teachers about this stage of development and production clothing product in the regional center of Londrina - PR. This research allowed the development of methodological guidelines for the teaching and preparation Modeling Industrial flat clothing.
\end{abstract}

Keywords: Fashion design; Production process; Flat Industrial Modeling; Guidelines methodology.

\section{Introdução}

No Brasil, o gênero industrial vestuário participa significativamente no crescimento econômico e no desenvolvimento do país, sendo responsável por cerca de $9 \%$ dos empregados da indústria de transformação nacional e ocupa um dos primeiros lugares na economia mundial com $14 \%$ dos empregos. Nesse cenário somente o Estado do Paraná representa $11,38 \%$ do total de empregados no segmento nacional (FIEP, 2009).

A indústria de confecção do vestuário atende uma necessidade básica do ser humano: o vestir. Nesse sentido, inserida na cadeia têxtil ela é responsável por todas as etapas relacionadas à produção do vestuário desde o beneficiamento das fibras têxteis até a 
confecção das peças prontas para o uso, sendo que a confecção é a última atividade antes da comercialização do produto.

Nesse processo de produção do vestuário a moda por meio do design é responsável pela diferenciação dos produtos buscando atender aos desejos, anseios e necessidades do consumidor. $\mathrm{O}$ design de moda possibilita a adaptação do produto às diferentes situações projetuais, como clima, tempo, local, costumes, cultura, inovações tecnológicas e eventos regionais, nacionais e internacionais (SOUZA, 2010).

$O$ design de moda pode ser definido com uma atividade de equipe com a função de desenvolver a inspiração, a percepção do possível, e a sua interpretação em termos de produtos que possam ser produzidos e comercializados. O seu uso eficaz pode servir como fonte de novas idéias auxiliando na redução de erros e do tempo de desenvolvimento de um produto industrial (SOUZA, 2010).

O suporte do produto do vestuário é o corpo humano, nesse sentido Martins (2006) relata que:

[...] assim como a pele está geneticamente adaptada ao corpo cumprindo as suas funções básicas e fundamentais; da mesma forma, o vestuário deve ser uma segunda pele que cobre o corpo, mas que precisa ser reconhecida e adaptada para os diferentes usuários em suas diferentes acepções.

A autora salienta a importância de estudos referentes à segunda pele - o vestuário. Nesse contexto um estudo aprofundado dos conhecimentos relacionados à elaboração do vestuário é relevante na relação do produto com o consumidor. A mesma autora ressalta ainda que no processo de criação, desenvolvimento e produção dos produtos de moda e vestuário, os designers e as indústrias produtoras nem sempre levam em consideração as necessidades de mobilidade do usuário e o conforto em relação às diferentes tarefas que realizam no seu cotidiano. O resultado são produtos que em muitos casos não atendem e nem se adaptam as necessidades desejadas pelos consumidores.

No processo de desenvolvimento do produto do vestuário uma etapa de grande responsabilidade pela adaptação do produto ao usuário é a modelagem plana industrial. A modelagem consiste numa atividade voltada para a planificação da roupa a fim de viabilizar a produção em escala industrial.

A modelagem no design do vestuário trata de uma atividade que atende às necessidades de conforto, durabilidade e funcionalidade do produto. Consiste em uma técnica responsável pela criação dos moldes, que reproduzem as formas e medidas do corpo humano, adaptados ao estilo proposto pelo designer. Elas são executadas a partir de uma análise feita pela modelista, profissional que elabora o molde- da interpretação do desenho técnico e das demais especificações do produto criado (JONES, 2005).

O processo de elaboração de um molde consiste numa fase que envolve os estudos dos fatores ergonômicos, da antropometria e o conhecimento do corpo do usuário. Assim, para realizar a modelagem plana industrial, os principais fatores a serem considerados são as formas, as medidas e os movimentos do corpo humano.

Grave (2004 apud MARTINS, 2006, p. 57) analisa que "uma roupa mal modelada expõe o corpo a alterações físicas, até mesmo doenças. Para tanto, é necessário um estudo pertinente para cada peça do vestuário". Assim, o processo de modelagem industrial determina por meio de suas características as formas, volumes, caimento, conforto que se configuram ao redor do corpo e deve, portanto analisar detalhadamente a morfologia do corpo e seus movimentos realizados. 
Nesse sentido, o problema central deste artigo, que derivou da pesquisa de mestrado em Design, é delinear diretrizes metodológicas para o processo de ensino da Modelagem plana Industrial, por meio da identificação da forma como vem sendo ensinada, aprendida, e aplicada nas instituições de ensino e nas indústrias do vestuário.

\section{Design de Moda}

A concepção de produto de moda envolve a articulação de fatores sociais, antropológicos, ecológicos, ergonômicos, tecnológicos e econômicos, em coerência às necessidades e desejos de um consumidor. Tal processo se encaixa na conduta criativa de resolução de problemas de design permitindo dessa forma a relação da moda com o design.

Moda é um fenômeno social e cultural, de caráter mais ou menos coercitivo, que consiste na mudança periódica de estilo, e cuja vitalidade provém da necessidade de conquistar ou manter uma determinada posição social. (JOFFILY, 1999 apud TREPTOW, 2003).

Rech (2002) conceitua o produto de moda como qualquer elemento ou serviço que conjuga "as propriedades de criação (design e tendências de moda), qualidade (conceitual e física), vestibilidade, aparência (apresentação) e preço, a partir das vontades e anseios do segmento de mercado ao qual o produto se destina", objetivando a satisfação das necessidades e expectativas do consumidor.

Afirma ainda que a moda, sendo um fenômeno social, acarreta mudanças sociológicas, psicológicas e estéticas, ligadas à arquitetura, artes, decoração e ao vestuário. Assim, quando se trata de alcançar tais requisitos, percebe-se a importância de aplicar os métodos de design durante o processo de desenvolvimento de produtos.

Dessa forma, o design de moda pode ser definido como sendo aquele que conjugue propriedades de criação, aspectos de formas, silhuetas, texturas, cores, materiais, emoções associando-se à soluções estéticas, funcionais e confortáveis. (PIRES, 2004).

Montemezzo (2003) afirma que o designer é o "emissor de uma mensagem, em forma de produto, e o consumidor/usuário do produto é o receptor da mensagem estética". A moda tem, especialmente, um caráter de expressar uma identidade singular, e tem ligação com o prazer de ver, mas também com o prazer de ser visto, de exibir-se ao olhar do outro.

Fornasier (2005), explica que a cada vez que se estruturam novos dados sociais (visão de novos competidores), progressos tecnológicos (transformação da matéria, difusão dos modelos) e desenvolvimentos econômicos (trocas comerciais, estruturas de distribuição), geram-se elementos para o design de moda.

Nesse sentido o design é uma expressão da sociedade atual, criador de diversidade e por isso, o seu investimento é fundamental para as características culturais dos cidadãos, sendo de suma importância no desenvolvimento dos produtos, de ambientes e dos serviços (CALDAS, 2004).

Desse modo ao considerar o design como um instrumento capaz de contribuir para a indústria junto à competitividade e como elemento diferenciador na qualidade dos produtos industriais, o designer de moda deve se conscientizar da importância e do caráter estratégico do design como elemento condicionante da competitividade das empresas produtoras do vestuário e de valor agregado ao produto. 


\section{O Processo de Modelagem Industrial}

Na materialização de um projeto de produto de moda, por meio da definição de tecidos, aviamentos, beneficiamentos, da elaboração de fichas técnicas, estudos de modelagens e pilotagens, os aspectos concretos são determinantes para a definição do tipo de produto. Todas essas atividades, assim como outras, se inter-relacionam e dependem umas das outras para o estabelecimento de uma coleção de produtos de moda (DENIS, 2004).

Porém, sabe-se que para um resultado satisfatório do produto de moda, ou seja, para que o mesmo atenda às expectativas do usuário, além da criatividade para desenvolver o desenho, o projetista deve tomar como base para a modelagem do vestuário, a percepção dos contornos do corpo, bem como suas medidas antropométricas.

Leite (2008) analisa que o processo de fabricação do vestuário é, acima de tudo, o resultado das informações de moda que resulta, posteriormente, em um produto. A moda está expressa nas mais diversas formas em diferentes áreas do conhecimento. Sendo assim o processo de modelagem industrial está diretamente ligada a materialização do produto desejado pelo usuário (LEITE, 2008).

A modelagem plana industrial é responsável pela materialização da idéia no produto, engloba as atividades relacionadas à execução das ferramentas - moldes necessárias à reprodução fiel das formas originais do projeto. Nesta etapa do desenvolvimento, deve-se seguir um planejamento com vistas à reprodução do produto em escala industrial, desenvolver uma sucessão estruturada de trabalhos interdisciplinares e de ações conjugadas, envolvendo também os setores relacionados com a produção e a comercialização dos produtos.

A modelagem, segundo Araújo (1996) consiste na "arte de confecção de moldes a partir de um modelo pré-estabelecido". Cabe ao modelista, por sua imaginação e capacidade de observação, ser capaz de adaptar, transformar e criar moldes, dentro daquilo que é o mais importante: a base do corpo. A modelagem tem como objetivo, adaptar a coleção à produção, por meio do desenvolvimento dos moldes, baseando-se o design do modelo, numa base de dados de moldes básicos, componentes normalizados e famílias ou blocos de moldes que representam o corpo humano.

A modelagem industrial é a técnica empregada na construção de roupas, sendo desenvolvida de forma bi ou tridimensional em quantas partes forem necessárias. Para isso o modelista faz a interpretação de todas as formas do corpo humano por meio de medidas antropométricas. Para a elaboração de modelagens de vestuários as principais referências que devem ser consideradas são os desenhos projetados pelos designers e principalmente as dimensões antropométricas do usuário, o corpo (MEDEIROS, 2007).

Radicetti (2004), respaldada nesses conhecimentos, afirma que o modelista, por meio das criações do designer, é capaz de desenvolver moldes de produtos que satisfaça os desejos estéticos, funcionais e emocionais dos consumidores. Woltz e Woltz (2006) analisa ainda que os desenhos criados pelos designers devam possuir uma total clareza de informação sobre a roupa permitindo a elaboração de produtos adequados ao consumidor. É a partir desses desenhos e pela ficha técnica de produto, que o modelista fará a interpretação e a elaboração dos moldes dos produtos.

O modelista faz a mediação entre a criação e a produção das peças em escala industrial, por isso é importante que todas as técnicas sejam avaliadas nesse processo, considerando que durante a produção industrial não será possível efetuar correções devido 
falhas da modelagem. A partir do momento que as partes das peças cortadas são levadas para a produção, não há mais retorno possível, a não ser que se refaça o molde e a peça piloto. (ESCOREL, 1999, p. 66).

\section{A Modelagem Plana}

A realização dos procedimentos técnicos da modelagem plana do vestuário parte do princípio da representação do corpo humano por meio de um plano. Esse se dá pelo posicionamento das linhas verticais e horizontais em ângulos, que se relacionam com o plano de equilíbrio do corpo, simetria, alturas, comprimentos e relações de proporções entre as partes.

A modelagem plana industrial, que pode ser realizada manualmente e por meio de sistemas computadorizados (CAD) utiliza os princípios da geometria para traçar os diagramas bidimensionais nos planos, esses denominados moldes, resultam em formas que se adaptaram ao corpo do usuário. Essas partes denominadas moldes, uma vez colocadas sobre o tecido, cortados e unidas por costuras resultarão nas vestimentas (SOUZA, 2006).

O molde traçado no papel de forma bidimensional, com auxilio de materiais e instrumentos de modelar, constitui-se por diagramas formados por ângulos de $90^{\circ}$ para garantir o equilíbrio da peça e por linhas retas e curvas, que vão tomando formas, obedecendo à tabela de medidas padronizadas para os diversos segmentos do design do vestuário.

A modelagem sofre diversas variações de acordo com o produto que será confeccionado, isso pode acontecer devido à variação de tipos diferenciados de tecidos que se vai trabalhar e que gera alterações na construção do molde. Esse processo é realizado por meio das folgas e encolhimentos que são necessários na elaboração de novos moldes.

A precisão das medidas antropométricas (estudo das medidas do corpo humano), o cálculo matemático apurado durante o traçado das bases, o uso das proporções entre as partes do corpo e o posicionamento das linhas de equilíbrio, podem fazer toda a diferença no caimento da roupa, e torná-la ergonomicamente projetada.

A tabela de medidas é imprescindível para a criação do molde base do vestuário. Esses se caracterizam por representar o corpo humano por meio de diagramas bidimensionais que costurados servirão de vestimenta. A partir desta base realizada pelo modelista, pode-se elaborar qualquer tipo de modelo e fazer as mudanças necessárias para a realização dos modelos desenhados pelos designers. Esse molde base faz toda diferença na produção industrial, já que a moda muda constantemente e novas modelagens se fazem necessárias a todo o momento. Desde que mantidas as bases e obedecendo a tabela de medidas, os moldes interpretados e realizados se adaptará bem ao consumidor (SOUZA, 2006).

Araújo (1996 apud SILVEIRA, 2008, p. 35) relata que:

\footnotetext{
Modelar consiste na interpretação das idéias do designer de moda e das informações registradas na ficha técnica do produto, onde constam dados importantes, como: tipo de tecido, linha, aviamentos, máquinas e, desenho técnico do produto, planificado e registrado de frente, costas e lateral, mostrando todos os detalhes a serem observados durante a modelagem e montagem da peça.
}

A modelagem no design do vestuário moderniza e proporciona leveza a criação, já que ao sair do papel e tornar-se tridimensional adapta-se ao corpo que o veste. As 
proporções devem ser estudadas precisamente, para que o detalhe escolhido seja realmente valorizado e todo o restante da obra sirva de suporte para este detalhe.

O desenvolvimento da modelagem plana industrial compreende as etapas descritas na Tabela 1, a seguir.

Tabela 1 - Etapas do desenvolvimento da modelagem

\begin{tabular}{|c|l|}
\hline Etapa & Atividade \\
\hline 1 & $\begin{array}{l}\text { Análise da tabela de medidas que será utilizada na realização dos modelos, de acordo com o público alvo da } \\
\text { empresa. }\end{array}$ \\
\hline 2 & $\begin{array}{l}\text { Traçado detalhado do diagrama base do corpo ( utilizando a tabela de medidas) que servirá de orientação } \\
\text { para a realização dos modelos criados pelos designers. O molde base facilita e agiliza o trabalho do } \\
\text { modelista pois sempre partirá de bases aprovadas para modelar novas peças. }\end{array}$ \\
\hline 3 & $\begin{array}{l}\text { Interpretação e elaboração dos modelos criados pelo designer de moda. Nessa fase o modelista a partir da } \\
\text { base faz as alterações na modelagem e cria o novo molde para o desenho criado. Tal análise é feita pelo } \\
\text { desenho técnico do produto que está na ficha técnica. }\end{array}$ \\
\hline 4 & Preparação da modelagem para a realização do corte das peça piloto. \\
\hline 5 & Análise e aprovação da peça piloto. \\
\hline 7 & Correção de moldes e execução de novas caso seja necessário. \\
\hline 8 & $\begin{array}{l}\text { Elaboração da modelagem final com devidas sinalizações para a produção em série. } \\
\text { tabela de medidas padrão. }\end{array}$ \\
\hline
\end{tabular}

Fonte: Souza (2006).

A ficha técnica é um referencial para integração dos ofícios de concepção e confecção do modelo - o principal veículo de comunicação entre o designer e o modelista na indústria - e sua transformação, de acordo com a seqüência do processo, vai estruturando o produto na medida do seu desenvolvimento e informando aos envolvidos a sua evolução no decorrer do processo. Suono adverte que:

a principal dificuldade no processo de desenvolvimento do produto de vestuário é a comunicação entre o desenho feito pelos designers, tendo como fonte o comercial, e os moldes feitos pelas modelistas, tendo como referencial a produção". (2007, p.87)

Assim pode-se observar que a modelagem se utiliza da tabela de medidas, dos conhecimentos da antropometria, da ergonomia e da matemática, com o auxilio dos conhecimentos da geometria e cálculos para o desempenho nos traçados dos moldes.

\section{Ergonomia e Modelagem}

O conceito de ergonomia pode ser compreendido a partir do pensamento de Iida (2005) como: "o estudo do relacionamento entre o homem e o seu trabalho, equipamento e ambiente, e particularmente a aplicação dos conhecimentos de anatomia, fisiologia e psicologia na solução dos problemas surgidos desse relacionamento.”

A ergonomia tem como objetivo prático a segurança, a satisfação e o bem-estar dos trabalhadores e clientes no seu relacionamento com os sistemas produtivos e com os produtos propriamente ditos.

No desenvolvimento de produtos de moda a ergonomia deve ser aplicada em todo o processo, uma vez que o objetivo da indústria do vestuário é projetar produtos de forma a conseguir melhor interação com o usuário. A utilização dos fatores ergonômicos vai além de 
uma investigação para a melhoria e organização do trabalho, deve reunir elementos e procedimentos, para adequar melhor os produtos ao gosto e à forma anatômica das pessoas.

A ergonomia aplica teorias, princípios, dados e métodos, que possam, previamente, preservar a vida humana, nos aspectos relativos à saúde, segurança, conforto e satisfação, quando aplicada ao projeto contribui para solucionar um grande número de problemas sociais, relacionados com a saúde, segurança, conforto e eficiência (WEERDMEESTER; DUL, 2001, p.13).

Nesse cenário ainda lida (2005), destaca as qualidades eficazes essenciais nos projetos de novos produtos:

- Qualidades técnicas, que dizem respeito à eficiência na realização da função principal;

- Qualidades ergonômicas, que tratam dos aspectos de conforto, segurança e facilidades de uso e manuseio do produto;

- Qualidades estéticas, as quais devem atrair e comunicar-se com o usuário/consumidor.

Analisando os pontos levantados pelo autor verifica-se que a ergonomia pode ser aplicada em todo o processo do desenvolvimento do produto do vestuário e em especial da modelagem, uma vez que, no processo de elaboração de novos produtos focaliza-se na utilização, no aprendizado, na eficiência, no conforto e na segurança objetivando atender as necessidades e desejos dos usuários. No produto de vestuário essa relação se estabelece da mesma forma, pois o mesmo busca, por meio de suas qualidades, agregar aspectos de caimento, estética e conforto, os quais constituem os requisitos de competitividade de maior peso para o design.

[...] os especialistas da área de ergonomia tem disponibilizado, cada vez mais, estudos e informações relevantes ao atendimento das necessidades físicas e psíquicas dos sujeitos que interagem com o mundo material humano. Pesquisas sobre antropometria, conforto térmico, ecodesign, ergonomia visual e emocional, mesmo que não tratem especificamente do produto de moda, podem ser o ponto de partida para a aplicação de fatores ergonômicos na sua concepção. (MONTEMEZZO,2003, p.49).

Ainda nesse sentido, Moraes (2001) trata da usabilidade como a adequação entre produtos e as tarefas cujo desempenho se destina, da adequação com o usuário que o utilizará e da adequação ao contexto que será usado. Afirma ainda que pode-se compreender usabilidade pela maximização da funcionalidade de um produto, na interface com seu usuário.

\begin{abstract}
A usabilidade representa a interface que possibilita a utilização eficaz dos produtos, tornado-os amigáveis e prazerosos durante o uso, em particular os produtos do vestuário. Os indicadores de usabilidade estão diretamente relacionados à facilidade de manejo, que por sua vez determina: a vestibilidade e a usabilidade da peça do vestuário, bem como o vestir, desvestir e acionar seus mecanismos de abertura, acesso ou fechamento da peça (MARTINS 2009, p. 13)
\end{abstract}

Sendo assim Moraes (2005 apud SILVEIRA, 2008, p. 99) define a usabilidade como "a efetividade, eficiência e satisfação com as quais usuários específicos atingem metas 
específicas em ambientes particulares". Analisando essa definição Silveira (2008), sintetiza o conceito pelo esquema abaixo, Figura 1, abaixo:

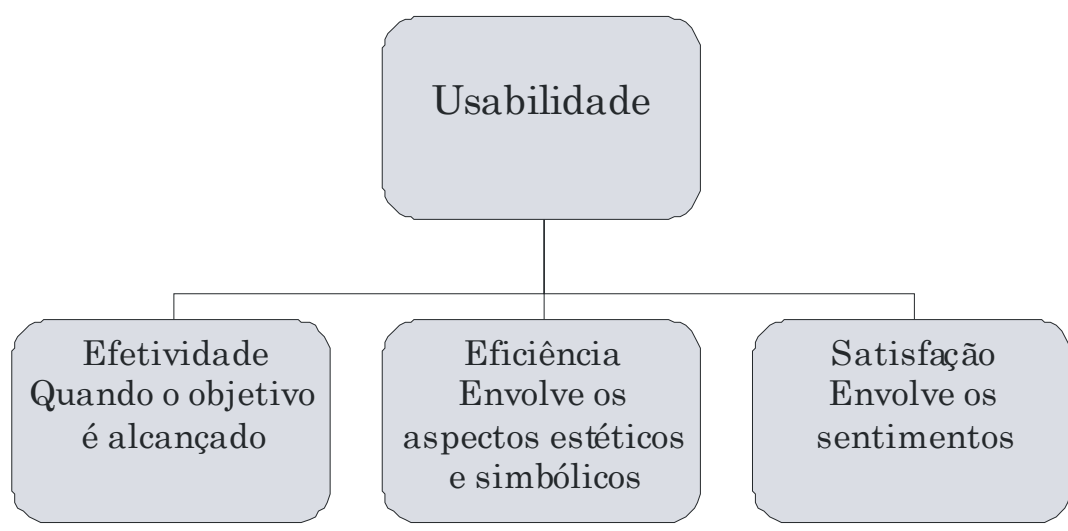

Figura 1 - Síntese do conceito da usabilidade

Fonte: Silveira (2008)

Ainda segundo a mesma autora, no desenvolvimento de produtos do vestuário, a efetividade de uma peça é atingida quando o objetivo pela qual ela foi proposto é alcançado, como por exemplo, uma roupa criada para atividades físicas que permita que seu usuário se movimente perfeitamente. Já a eficiência está relacionada com a satisfação do usuário por uma necessidade no produto, como por exemplo, um recurso de abertura da peça que facilitou ou melhorou o cotidiano do usuário. E a satisfação relaciona-se ao nível de conforto e aceitabilidade do usuário ao usar o produto e envolve os sentimentos que ele teve na mesma situação.

No processo de criação e desenvolvimento de produtos de moda a aplicação dos princípios ergonômicos, da usabilidade e do conforto é essencial, já que neles devem ser considerados princípios como anatomia humana, fisiologia, antropometria, psicologia e sociologia, fatores que são pertinentes na concepção de qualquer produto direcionado ao homem.

Assim ressalta-se a importância de enfatizar a ergonomia em todo o processo de elaboração e produção do produto de moda. As preocupações com a ergonomia que devem ser adotadas nessas fases, auxiliará na elaboração de um produto de vestuário mais significativo no conforto e bem-estar de seu consumidor. Com relação à modelagem a autora relata que a preocupação com a ergonomia está relacionada diretamente com a segurança, liberdade de movimentos (conforto), conforto tátil e conforto térmico principalmente.

Assim, a aplicação dos conceitos referentes à ergonomia, usabilidade e conforto durante o processo de realização da modelagem plana industrial auxiliará na elaboração de moldes voltados ao consumidor, já que, pensará nos princípios ergonômicos desde sua concepção.

\section{Antropometria}

A antropometria consiste na ciência que levanta dados das diversas dimensões corporais existentes em sua totalidade, tamanhos, proporções, volumes, formas, movimentos e articulações. lida (2005, p. 97) afirma tal informação quando diz que a antropometria "trata das medidas físicas corporais, em termos de tamanho e proporções" 
que são bases para a concepção e aplicação dos princípios ergonômicos. Relata ainda que para que um produto possa ser considerado ergonomicamente qualificado ele deve passar por uma adequação antropométrica.

No desenvolvimento de novos projetos e equipamentos a antropometria é suporte na adequação do produto ao seu usuário sendo ferramenta para resolução de problemas de design. Esse processo de adaptação do produto ao usuário é um dos principais fatores de diferenciação e inovação no mercado.

No âmbito do design de moda as análises corporais antropométricas devem ser suporte para a construção da modelagem industrial. A aplicação dessas medidas na construção do vestuário deve estar presente desde antes de sua concepção, na fase inicial da elaboração do projeto do produto, já que é responsável pelo conhecimento do corpo do usuário. A aplicação da antropometria no vestuário no processo da indústria de confecção deve ser efetuado uma pesquisa detalhada com o público identificando suas características físicas e suas necessidades.

[...] para a elaboração de produtos de moda, a indústria, através da modelista, precisa de uma tabela de medidas, um referencial que o profissional da área deverá seguir para que as peças se encaixem de maneira adequada no perfil físico usuários que irão adquiri-las (CAPELASSI, 2010, p. 26).

O vestuário cria uma relação íntima com seu usuário e por isso ele deve envolver uma comunicação completa com o corpo e em muitos casos de afeto. Assim no planejamento da peça de vestuário é importante considerar e respeitar as características antropométricas de cada indivíduo (GRAVE, 2004).

De acordo com lida (2005), a ergonomia analisa que todos os produtos estão destinados a satisfazer certas necessidades humanas e, direta ou indiretamente, estabelecem vínculos. Para que isto ocorra da melhor forma, é necessário que o produto apresente características técnicas, estéticas e ergonômicas. Partindo da definição de lida e relacionando-a com a antropometria e modelagem, confere-se a qualidade ergonômica como princípio aplicável aos produtos de vestuário.

Entretanto, ao aprofundar este conceito, percebe-se que a qualidade ergonômica se inter-relaciona com a qualidade estética do vestuário, eis que a primeira influencia no resultado da segunda. Quando um vestuário não está adequado ao tipo de corpo do usuário, questões relacionadas ao ajuste e caimento da peça, bem-vestir e sensação de conforto comprometem também a qualidade estética do produto.

Desse modo, a ciência das medidas humanas é significativa para a indústria do vestuário de forma coletiva, pois além dos aspectos ergonômicos e estéticos, é preciso um único tamanho de vestuário vestir adequadamente diversos tipos de corpo, o que é exigido pelas necessidades da produção em massa (CAPELASSI, 2010, p. 26).

A aplicação dos dados antropométricos de forma adequada é que poderá garantir a satisfação do usuário. Um mesmo produto precisa ser projetado para se adaptar às diferenças antropométricas de diversos corpos, assim as indústrias de confecções precisa conhecer o corpo dos seus consumidores para que não ocorram problemas de usabilidade e conforto (SILVEIRA, 2008). Nesse sentido na visão de lida $(2005$, p.98) deve-se "definir a natureza antropométrica exigida em cada situação; realizar medições, utilizando critérios, para gerar dados confiáveis; e aplicar adequadamente esses dados".

Dessa forma considerando o corpo humano como ponto de partida para um adequado desenvolvimento de produto, é fundamental relevar as relações entre diferentes 
dimensões corporais, algumas das quais são necessárias para a construção do produto roupa, tais como altura do corpo, circunferência do busto e da cintura, largura do ombro e das costas, entre cavas e pescoço, para a parte superior do corpo; e circunferência do quadril, gancho, altura do joelho e tornozelo, para os membros inferiores.

De tal modo, a antropometria tem a finalidade de ajudar o designer de moda a tomar consciência da importância das dimensões humanas no projeto e a estabelecer um vínculo entre antropometria e o projeto de vestuário. Dados antropométricos adequados ao usuário e aplicados na etapa de concepção do produto reduzem o risco da indústria ter problemas referentes aos fatores relacionados a conforto, tamanho inadequado e usabilidade do produto (PANERO; ZELNIK, 2002).

Do exposto, pode-se entender que o produto de moda/vestuário está presente na maior parte do tempo como uma extensão do próprio corpo. Por isso, o conhecimento da anatomia e o estudo das dimensões corporais são primordiais para o projeto, tendo em vista o desempenho de uso. Assim em se tratando de moda e vestuário é fundamental considerar as necessidades e anseios dos consumidores realizando os estudos e adaptações necessárias para o seu planejamento e elaboração.

\section{O Corpo Usuário}

Barboza (2007) relata que o "o corpo humano pode ser definido como uma estrutura complexa, um "conjunto de órgãos, revestido de ossos e músculos", realizando dessa forma as funções vitais que mantém o ser humano em pleno funcionamento diariamente. Essa definição relatada pela autora acaba excluindo a riqueza do corpo e de seus movimentos, expressões e de suas linguagens.

O corpo como suporte da vestimenta, habita e ocupa seu interior estabelecendo com ele uma leitura social e estética. Martins (2008) estabelece uma visão do mundo por meio de cinco peles distintas, a primeira a epiderme (pele), a segunda o vestuário, a terceira o habitat do homem, a quarta o meio social e a identidade e a quinta a humanidade, a natureza e o meio ambiente. Essas cinco peles se fundem para que o homem possa construir uma identidade única, habitando o espaço físico e o território que determine sua existência.

Numa análise mais ampla em relação ao corpo no desenvolvimento do produto de moda cabe identificar toda a gama de movimentos produzidos por ele, as expressões corporais, sua relação com a matéria - prima utilizada na elaboração de novos produtos do vestuário, segunda pele, possibilitando a adequação de recursos ao corpo usuário, e também a análise das linguagens e sentidos produzidos por esse corpo envolvido pela moda (BARBOZA, 2007).

Nesse sentido, o corpo é objeto de estudo de diversas ciências, como a medicina, a psicologia, a filosofia, a moda, entre outras. Cada uma dessas áreas contribui para a compreensão de diferentes aspectos relativos ao assunto, colaborando para o processo de construção do conhecimento cientifico.

Pensar no corpo pode ter diversos sentidos. Cada ciência, cada cultura, cada pessoa pode percebê-lo e vivenciá-lo de diversas maneiras. Códigos, práticas, instrumentos sociais e culturais são efetivados, concentrados e refletidos através do corpo. Trata-se de um quadro vivo, de certa forma, contido por normas que o transformam, revelando regras e costumes causados por uma ordem social (SOARES, 2001).

Essa relação do corpo com o aspecto sensitivo, cultural e social implica conceber outros conceitos na construção do conhecimento sobre o corpo. Um desses é a 
corporeidade, que de acordo com Moreira (2003), consiste na contemplação do sensível, o inteligível e o motor. Trata-se também de um corpo que busca qualidade de vida, que vai além dos limites que a anatomia e a fisiologia lhe impõem, sendo construído nas relações sócio-históricas e trazendo em si uma marca de individualidade.

Dessa forma, o corpo estende-se pelos instrumentos criados pelo ser humano por meio das roupas e da cultura. Ao conferir aos instrumentos um significado, as pessoas passam por um processo de aprendizagem construtor de hábitos. Expressivo e significativo, o corpo não é um simples conjunto de órgãos, e sim uma permanente vivência que se move em direção ao mundo com objetivos sociais.

A partir disso, pode-se considerar o corpo como uma imagem social, como uma forma de exprimir um corpo inserido no mundo. Considerando que esse corpo concebe todas as sensações vindas de dentro e fora do organismo, essas imagens estão presentes nos afetos, nos valores e na história pessoal marcada por gestos, olhares; no corpo que se move que repousa e que simboliza todas essas ações (FREITAS, 1999).

Diante disso, é necessário também o conhecimento da estrutura básica do corpo para suporte para a pesquisa dos projetos do desenvolvimento de roupas, segundo Grave (2004 apud SOUZA, 2006, p. 45) "o ombro funciona como um pêndulo em relação ao eixo do quadril e contribui com o equilíbrio do corpo, tornando significativo o movimento do vestuário na parte superior e por sua vez, afirma que o quadril participa da mobilidade, porém gerando menos movimentação".

\begin{abstract}
Nos membros superiores - braço, cotovelo, antebraço, punho e mão - e nos inferiores - coxa, joelho, perna, tornozelo e pé - as articulações, que são os pontos de união dos ossos, proporcionam a mobilidade, mediante a ação dos músculos. Os músculos são, portanto, os responsáveis pelos movimentos do corpo: são os elementos ativos do movimento, enquanto os ossos são os elementos passivos. As articulações condicionam o movimento das várias partes do corpo, estabelecendo em cada caso, valores máximos de angulação (em graus) e determinando o tipo de mobilidade. Existem vários tipos de movimentos articulares, a saber: flexão, extensão, adução, abdução, rotação e circundação (SOUZA, 2006, p.45).
\end{abstract}

Nesse sentido social e biológico, no projeto de produto de moda o corpo deve ser considerado em seus termos anatômicos, sensoriais e suas possibilidades de movimento, pontos esses fundamentais que interferem no desenvolvimento da modelagem. Tendo em vista que, o resultado irá ocorrer diretamente sobre a percepção do usuário que vivenciará as sensações provocadas pela roupa. Assim é preciso tomar conhecimento de todo o funcionamento de cada parte do corpo para que o vestuário possa contribuir com o bom desempenho do usuário, fator esse categórico na concepção do produto (BARBOZA, 2007).

Nesse aspecto a roupa é um objeto têxtil capaz de permitir ou bloquear os movimentos de quem a usa e deve cumprir as necessidades ergonômicas desejadas, sendo elas proteção, segurança, conforto e mobilidade.

Segundo Souza (2006) inúmeras são as possibilidades construtivas de elaboração de uma vestimenta adaptada ao corpo, mas a conformação da vestimenta ao corpo está diretamente relacionada com os materiais aplicados e com as soluções construtivas (modelagens) e estruturais utilizadas que possibilitam o movimento do corpo. 
O corpo ereto constitui-se tridimensionalmente e pode ser figurado em pelo menos três modos básicos: de frente, de lado e de costas. [...] É por meio da análise dessas três possibilidades de vizualização do corpo que podem ser traçadas suas linhas de movimentação, articulação e de constituição plástica - e as relações provenientes da junção com os trajes. (SOUZA, 2006, p. 41 apud CASTILHO, 2004, p. 63).

Na relação do corpo com a vestimenta é importante analisar o espaço entre eles. 0 espaço e a forma da vestimenta são os responsáveis por permitir a resolução de problemas que a vestimenta busca em reposta a condições de função, propósito e contexto (SOUZA, 2006 apud CHING, 2002, p. IX).

Assim, a vestimenta concebida como segunda pele deve ter como objetivo fundamental o conforto. O corpo não deve ser restringido por uma roupa ou por quaisquer outros fatores em seus movimentos, uma vez que sua liberdade é que trás bem-estar ao usuário. Dessa forma analisando o corpo e sua relação com o vestuário é possível verificar a importância da exploração da modelagem, do material têxtil, das criações do designer e as técnicas de confecção para a elaboração do produto de moda.

\section{Os Procedimentos Metodológicos Adotados para a Investigação}

Visando dar suporte para a compreensão do problema do trabalho em questão aplicou-se uma pesquisa de caráter qualitativo envolvendo: empresas no pólo industrial de Londrina-PR, estudantes e docentes. Trata-se de uma pesquisa social, de caráter empírico definida como uma metodologia de coleta de dados amplamente empregada (BAUER; GASKELL, 2002).

A mesma buscou identificar o contexto atual no processo de desenvolvimento de modelagem plana industrial. Para tanto se utilizou de protocolos com perguntas abertas e individuais, mediante estudo de caso, com o intuito de identificar o cenário do problema em questão. A finalidade dessa pesquisa foi explorar o espectro de opiniões e as diferentes visões referentes à modelagem plana industrial, visando identificar como tem se dado o processo de ensino de modelagem plana industrial em uma fase que antecede ao aprendizado do traçado dos moldes, e verificar os conteúdos que são levados em consideração no desenvolvimento de novas modelagens. Ou seja, identificar a forma como vem sendo ensinada, aprendida e aplicada à modelagem plana industrial nas instituições de ensino e nas indústrias do vestuário.

A pesquisa constitui-se de levantamento por interrogar diretamente os envolvidos na problemática verificada e também participante, pois foi de plena interação entre as partes. Todos os participantes da pesquisa foram esclarecidos e assinaram o "Termo de Consentimento Livre e Esclarecido".

Participaram da pesquisa 06 empresas de vestuário da região de Londrina-PR, de todos os segmentos, de pequeno porte e que tinham todas as etapas do processo produtivo que envolve a atuação do profissional modelista.

Além desses participantes o protocolo foi aplicado a 06 docentes da área, que ministram ou ministraram disciplinas de modelagem nos últimos dois anos. Também participaram da pesquisa 15 estudantes dos últimos dois semestres de cursos superiores de moda da mesma região para identificar os conhecimentos dos mesmos, relacionados ao problema em questão. 
A aplicação da pesquisa direcionada a profissionais da área, docentes e estudantes permitiu uma visão ampla do atual cenário no processo de ensino e desenvolvimento da modelagem plana industrial.

\section{A Discussão dos Resultados}

A análise dos dados coletados com os protocolos aplicados junto aos modelistas, docentes e alunos mostraram a visão de cada grupo com relação aos conhecimentos utilizados na elaboração, no ensino e no aprendizado da modelagem plana industrial. Nesse sentido, a partir da revisão de literatura e a com os dados da pesquisa existem alguns pontos que devem ser preocupação constante nesse processo, sendo eles a ergonomia, a antropometria e o corpo usuário.

Discutindo a preocupação com a ergonomia: com relação às preocupações com a ergonomia no desenvolvimento da modelagem plana industrial os protocolos possibilitaram três análises significativas.

Nos protocolos aplicados aos modelistas, os principais pontos levantados relativos à ergonomia foram:

- A ergonomia quando analisada é verificada somente no momento da aprovação das peças;

- Preocupação superficial com os aspectos ergonômicos na elaboração dos moldes.

Nos protocolos aplicados junto aos docentes identificou-se que todos acreditam que a ergonomia é um fator importante no processo de aprendizado da modelagem antes do ensino do traçado do molde. Porém, analisando os conteúdos que os mesmos julgam importante para esse aprendizado a ergonomia não aparece como um ponto que deve ser ensinado antes dessa fase de aprendizado.

Com relação ao protocolo direcionado aos alunos foi identificado que eles conhecem os aspectos significativos da aplicação da ergonomia no desenvolvimento de um molde. Entretanto, quando questionados se eles levam em consideração na elaboração de suas modelagens, as respostas mostraram que eles têm dificuldade de aplicar esses aspectos no momento que estão executando seus moldes.

Analisando as respostas identificadas com os protocolos dos modelistas, docentes e alunos e com suporte nos pontos levantados na revisão de literatura foi possível verificar que no processo de ensino da modelagem a ergonomia vem sendo levada em consideração, porém isso não tem acontecido sempre antes do traçado do molde.

Assim o ponto significativo nessa análise é a dificuldade que os alunos e os modelistas mostraram nas pesquisas em aplicar a ergonomia na fase de elaboração dos moldes. Isso mostra que a forma como foi ensinada ou ainda como vem sendo aplicada não tem sido suporte suficiente no processo de adequação desses aspectos na construção do molde do vestuário.

Discutindo a preocupação com o corpo usuário: analisando as questões respondidas pelos modelistas, docentes e alunos relacionadas à preocupação do conhecimento do corpo usuário para a elaboração dos moldes foi possível identificar alguns pontos específicos.

Os modelistas responderam que na elaboração das modelagens com relação ao corpo do consumidor, eles se preocupam que seus clientes gostem da peça, que a roupa 
vista bem, com o conforto e com o caimento. Um modelista justificou que como elabora peças sazonais, não consegue sempre levar em consideração as preocupações de vestibilidade do corpo.

Os docentes informaram que acham importante o aprendizado das questões que envolvem a preocupação com o corpo usuário antes do aprendizado dos traçados dos moldes, porém alguns informaram que o assunto pode ser mais aprofundado.

As respostas dos alunos com relação a esse assunto mostram que os mesmos acreditam que o corpo usuário deve ser estudado profundamente no processo de aprendizagem da modelagem levando em consideração fatores como: vestibilidade, conforto, movimentos, usabilidade, necessidades físicas, flexibilidade, necessidades estéticas e facilidades de uso. Informam ainda que esses são assuntos que devem ser amplamente estudados antes, durante e depois do aprendizado do traçado de um molde.

Discutindo a preocupação com a antropometria: com relação às preocupações com a antropometria no desenvolvimento de um molde e nos conhecimentos relacionadas e ela no processo de modelagem industrial os protocolos possibilitaram pareceres dos pontos de vistas dos modelistas, docentes e alunos.

Com relação às respostas dos modelistas pode-se identificar que a preocupação com a antropometria direciona-se a basicamente a aplicação de tabelas de medidas que não são a realidade do público-alvo da empresa.

A mesma análise do ponto de vista dos docentes mostra que todos acreditam na importância do ensino da antropometria no processo de aprendizagem da modelagem, porém acreditam que esse pode ser mais aprofundado durante a fase que antecede ao aprendizado do traçado de um molde.

As respostas dos alunos mostram que todos acreditam que a antropometria deve ser suporte na adaptação das medidas do público ao usuário e que deve ajudar na fase de elaboração de um molde, porém analisam a importância do aprofundamento do assunto devido as dificuldades de pensar em todos os aspectos antropométricos no momento da execução de um molde.

\section{A Análise comparativa dos protocolos aplicados}

Analisando os protocolos a principal informação identificada no questionário com os modelistas é que todos conhecem o algum ponto importante no processo de desenvolvimento de modelagem plana industrial, porém sua aplicação prática acontece de forma superficial. Tal levantamento foi possível principalmente pela questão que analisava se no desenvolvimento da modelagem eles levavam em consideração os aspectos da ergonomia, da antropometria e do corpo usuário. As respostas mostraram que quase todos eles elaboram suas modelagens no trabalho diário desconsiderando todos esses fatores.

No questionário aplicado aos docentes a informação mais significativa da pesquisa foi identificada com as respostas referentes ao ensino da ergonomia, antropometria, geometria e do conhecimento do corpo usuário. Nessa questão os docentes responderam que acreditam que tais assuntos são importantes e que devem ser considerados no processo de aprendizado da modelagem, porém ponderam a importância de aprofundar esses conhecimentos nessa fase do ensino.

Com relação aos protocolos dos alunos, principalmente, duas questões foram significativas para a pesquisa. Uma delas questionava quais os tipos de conteúdos que os 
alunos julgavam necessários conhecerem antes de aprender o processo de traçado dos moldes. A outra questionava se eles acreditavam desenvolver moldes considerando os aspectos da ergonomia, antropometria, e corpo do usuário. Os resultados dessas duas questões mostram que apesar de conhecerem os fatores de forma mais detalhada para desenvolvimento de uma modelagem adequada nem sempre eles são levados em consideração em todos os moldes realizados.

A pesquisa realizada nesse trabalho possibilitou identificar que no âmbito acadêmico os pontos essenciais para a elaboração da modelagem são ensinados e conhecidos pelos alunos e vem sendo explorados no processo de construção de um molde.

Analisando as respostas dos modelistas o que foi identificado que existe uma distância maior do conhecimento necessário para desenvolver um molde daquele que é praticado na elaboração de um molde na indústria do vestuário.

Tais levantamentos mostraram que os cenários da academia e da indústria, apesar de terem dificuldades na aplicação desses conhecimentos no desenvolvimento prático de um molde, ainda estão distantes um do outro no que se refere aos conhecimentos necessários para a realização da modelagem.

Assim, os protocolos aplicados possibilitaram identificar e comprovar os objetivos propostas da pesquisa em questão e principalmente a forma como vem sendo ensinada, aprendida e aplicada à modelagem plana industrial na indústria do vestuário e nas instituições de ensino.

\section{As Diretrizes Metodológicas para o Processo de Ensino da Modelagem Plana Industrial}

De acordo com os dados levantados por meio da revisão de literatura e com os protocolos aplicados, a pesquisa sugere as "Diretrizes Metodológicas para o Processo de Ensino da Modelagem Plana Industrial", que objetiva dar suporte aos conhecimentos que devem ser ensinados antes do processo de aprendizado do traçado do molde. Essas diretrizes podem ser utilizadas tanto na fase de ensino da modelagem como devem ser consideradas durante a realização dos moldes pelos alunos e modelistas.

As Diretrizes metodológicas para o processo de ensino da Modelagem plana Industrial exploram os seguintes fatores:

\begin{tabular}{|c|c|c|c|}
\hline FATORES & $\begin{array}{c}\text { FASE DO } \\
\text { APRENDIZADO }\end{array}$ & $\begin{array}{l}\text { ASPECTOS A SEREM } \\
\text { CONSIDERADOS }\end{array}$ & APLICAÇÕES \\
\hline \multirow{8}{*}{ ERGONÔMICOS } & \multirow{8}{*}{$\begin{array}{l}\text { Antes do aprendizado } \\
\text { traçado do molde }\end{array}$} & $\begin{array}{c}\text { Conforto: físico, fisiológico, } \\
\text { psicológico, tátil, térmico, } \\
\text { visual }\end{array}$ & \multirow{8}{*}{$\begin{array}{l}\text { Durante o aprendizado } \\
\text { da modelagem e durante } \\
\text { sua execução }\end{array}$} \\
\hline & & $\begin{array}{l}\text { Usabilidade: efetividade, } \\
\text { eficiência e satisfação }\end{array}$ & \\
\hline & & Segurança & \\
\hline & & Vestibilidade e funcionalidade & \\
\hline & & $\begin{array}{c}\text { Necessidades: físicas e } \\
\text { psíquicas }\end{array}$ & \\
\hline & & Liberdade de movimentos & \\
\hline & & Escolha de materiais & \\
\hline & & Forma e caimento & \\
\hline \multirow[b]{2}{*}{ ANTROPOMÉTRICOS } & \multirow[b]{2}{*}{ Antes do aprendizado } & $\begin{array}{l}\text { Compatibilidade das medidas } \\
\text { corporais do usuário ao } \\
\text { produto }\end{array}$ & \multirow[b]{2}{*}{ Durante $o$ aprendizado } \\
\hline & & Tipos de estruturas corporais: & \\
\hline
\end{tabular}




\begin{tabular}{|c|c|c|c|}
\hline & \multirow[t]{4}{*}{ traçado do molde } & tamanhos & \multirow{4}{*}{$\begin{array}{l}\text { da modelagem e durante } \\
\text { sua execução }\end{array}$} \\
\hline & & Proporção corporal & \\
\hline & & Volume corporal & \\
\hline & & Forma corporal & \\
\hline \multirow{12}{*}{ CORPO USUÁRIO } & \multirow{12}{*}{$\begin{array}{l}\text { Antes do aprendizado } \\
\text { traçado do molde }\end{array}$} & Movimentos & \multirow{12}{*}{$\begin{array}{l}\text { Durante o aprendizado } \\
\text { da modelagem e durante } \\
\text { sua execução }\end{array}$} \\
\hline & & Articulações & \\
\hline & & Expressões corporais & \\
\hline & & Linguagens e sentidos & \\
\hline & & $\begin{array}{c}\text { Relação sensitiva, cultural e } \\
\text { social }\end{array}$ & \\
\hline & & Anatomia e fisiologia & \\
\hline & & Estruturas básicas corporais & \\
\hline & & Constituição plástica & \\
\hline & & Proporção humana & \\
\hline & & Adequação formal /vestimenta & \\
\hline & & Relação corpo/vestimenta & \\
\hline & & Espaço corpo e roupa & \\
\hline \multirow{3}{*}{ GEOMÉTRICOS } & \multirow{3}{*}{$\begin{array}{l}\text { Antes do aprendizado } \\
\text { traçado do molde }\end{array}$} & Noções matemáticas & \multirow{3}{*}{$\begin{array}{l}\text { Durante o aprendizado } \\
\text { da modelagem e durante } \\
\text { sua execução }\end{array}$} \\
\hline & & Noções angulares & \\
\hline & & Noções geométricas & \\
\hline
\end{tabular}

\section{Conclusão}

Esse estudo nasceu da necessidade identificada pela autora desta pesquisa na atuação como docente, profissional da área e aluna em identificar e confirmar se suas vivências adquiridas aconteciam durante o processo de ensino-aprendizado e na elaboração da modelagem plana no âmbito acadêmico e industrial.

As experiências vivenciadas pela autora da presente pesquisa como aluna, docente e profissional da indústria de confecção, com relação à modelagem plana industrial, permitiram identificar a necessidade de um estudo direcionado aos conhecimentos necessários para o entendimento do processo de desenvolvimento da modelagem.

Tal experiência possibilitou verificar que os problemas no desenvolvimento da modelagem no âmbito acadêmico e industrial podem ser similares se não forem considerados os pontos fundamentais para o desenvolvimento de um molde.

A pesquisa identificou a forma como é aplicada a ergonomia, a antropometria e a preocupação com o corpo usuário em todos os âmbitos de desenvolvimento de um molde, academia/indústria. Essa análise permitiu identificar que esses fatores são levados em consideração no processo de ensino-aprendizado e na aplicação na indústria pelo modelista, porém os conhecimentos que os alunos e modelistas aplicam em muitos casos, não são suficientes para a elaboração de moldes mais adequados ao consumidor.

Pelo estudo, análise e comparação promovidos pela revisão de literatura e pelos protocolos aplicados, diagnosticou-se que o processo de elaboração da modelagem depende dos pré-conhecimentos adquiridos antes do aprendizado do traçado do molde.

Um ponto importante identificado com a pesquisa e confirmado pelas vivências práticas da autora da referida pesquisa é a necessidade de estudos referentes à geometria e suas definições e aplicações antes do aprendizado do traçado do molde.

Sendo assim, a presente pesquisa sugere que a ergonomia, a antropometria, a análise do corpo usuário e a geometria sejam conhecimentos teóricos que devem ser aprendidos antes do processo de aprendizado de um molde. Esses conhecimentos devem 
ser amplamente explorados e devem ser aplicados em todas as fases de construção da modelagem.

Assim, as diretrizes sugeridas neste trabalho podem ser utilizadas tanto na fase de ensino da modelagem, assim como serem consideradas durante a realização dos moldes pelos alunos e modelistas.

Com relação aos modelistas que já estão nas indústrias do vestuário à pesquisa identificou a necessidade de atualização de seus conhecimentos, devido à dificuldade que alguns possuem em aplicar os aspectos ergonômicos, antropométricas e referentes ao corpo usuário no desenvolvimento de um molde.

Assim pode-se concluir com o referido trabalho, que para o desenvolvimento da modelagem plana industrial depende-se dos conhecimentos da antropometria, da ergonomia e da geometria. Logo, os objetivos da seguinte pesquisa foram alcançados, deixando em aberto um novo campo de estudo para novos trabalhos na área.

\section{Referências}

ARAÚJO, Mário. Tecnologia do vestuário. Lisboa: Fundação Calouste Gulbenkian, 1996.

BARBOZA, L. M. Relações, corpo, forma e têxtil: valorização do corpo como estrutura sensível. Londrina, 2007. Trabalho de Conclusão de Curso (graduação em Estilismo em Moda) - Universidade Estadual de Londrina.

BAUER, Martin W.; GASKELL, George. Pesquisa qualitativa com texto: imagem e som: um manual prático. Petrópolis, RJ: Vozes, 2002.

CALDAS, Dario. Observatório de sinais: teoria e prática da pesquisa de tendências. Rio de Janeiro: Senac Rio, 2004.

CAPELASSI, Carla Hidalgo. Metodologia projetual para produtos de moda e a sua interface com as tabelas de medidas do vestuário. Bauru, 2010. Dissertação (Mestrado em Design) Universidade Estadual Paulista.

CASTILHO, Kathia. Moda e linguagem. São Paulo: Anhembi Morumbi, 2004. (Moda e Comunicação).

CASTILHO, Kathia; GALVÃO, Diana (Org.). A moda do corpo, o corpo da moda. São Paulo: Esfera, 2002.

CASTILHO, Kathia; MARTINS, Marcelo M. Discursos da moda: semiótica, design e corpo. 2. ed. São Paulo: Anhembi Morumbi, 2005.

DENIS, Rafael Cardoso. Uma introdução a história do design. 2.ed. São Paulo: Edgard Blucher, 2004.

ESCOREL, Ana. O efeito multiplicador do design. São Paulo: Senac, 2000. 
EMÍDIO, Lucimar de Fátima Bilmaia. A gestão de design como ferramenta estratégica para MPEs do vestuário de moda: um estudo de caso na região de Londrina. Bauru, 2006. Dissertação (Mestrado em Desenho Industrial) - Universidade Estadual Paulista.

FEDERAÇÃO DAS INDÚSTRIAS DO ESTADO DO PARANÁ (FIEP). Indústria do Vestuário do Paraná. Curitiba,set., 2008. Disponível em <http://www.fiepr.org.br/fiepr/analise/panr ama/vestu\%C3\%A1rio.pdf>. Acesso em 23 out. 2009.

FORNASIER, Cleuza Bittencourt Ribas. Modelo organizacional de autogestão para projetos sociais: uma ação de design. Florianópolis, 2005. 148f. Dissertação (Mestrado em Engenharia de Produção) - Universidade Federal de Santa Catarina, 2005.

FREITAS, Giovanina Gomes. O esquema corporal, a imagem corporal, a consciência corporal e a corporeidade. ljuí. UNIJUÍ, 1999.

GRAVE, Maria de Fátima. A modelagem sob a ótica da ergonomia. São Paulo:Zennex, 2004.

IIDA, Itiro. Ergonomia: projeto e produção. São Paulo: Edgard Blucher, 2005.

JONES, Sue Jenkyn. Fashion design: manual do estilista. Tradução de lara Biderman. São Paulo: Cosac Naify, 2005.

LEITE, Iracema Tatiana Ribeiro; LIMA, Marcondes. Recriando o corpo feminino: sedução, fantasia e ideal de beleza. In: COLÓQUIO DE MODA, 3., 2007, Anais... São Paulo, 2007. Disponível em: http://www.coloquiomoda.com.br/coloquio2007/anais_aprovados/recriando_o_corpo_fem inino_seducao_fantasia_e_ideal_de_beleza.pdf. Acessado em Maio de 2008.

MAFFEI, Simone Thereza Alexandrino. O produto de moda para o portador de deficiência física: análise de desconforto. Bauru, 2010. 90 p. Dissertação (Mestrado em Desenho Industrial) - Universidade Estadual Paulista.

MARTINS, Suzana Barreto. O conforto no vestuário: uma interpretação da ergonomia: metodologia de avaliação de usabilidade e conforto no vestuário. 2005. Tese (Doutorado em Engenharia de Produção) - Universidade Federal de Santa Catarina, Florianópolis, 2005.

. Equação da ergonomia no design de vestuário: espaço do corpo, modelagem e matérias. In: CONGRESSO BRASILEIRO DE ERGONOMIA - ABERGO, 14., 2006, Curitiba - PR . Anais... Curitiba: ABERGO, 2006.

MEDEIROS, Maria de Jesus Farias. Produto de moda: modelagem industrial com aspectos do design e da ergonomia. Palermo, Universidade de Palermo, 2007.

MONTEMEZZO, Maria Celeste de Fátima Sanches. Diretrizes metodológicas para o projeto de produtos de moda no âmbito acadêmico. 2003. 97 f. Dissertação (Mestrado em Desenho Industrial) - Universidade Estadual Paulista, Bauru, 2003. 
MORAES, Anamaria de. Ergonomia e usabilidade de produtos, programas, informação. In: MORAES, Anamaria de; FRISONI, Bianka Capucci. Ergodesign: produtos e processos. Rio de Janeiro: 2AB, 2001. p. 195-206.

MOREIRA, Wagner Wey. Corporeidade e lazer: a perda do sentimento de culpa. Revista Brasileira de Ciência e Movimento, Brasília, v. 11, p. 85-90 2003.

NACIF, Marcia de Araujo Leite; VIEBIG, Renata Furlan. Avaliação antropométrica nos ciclos da vida: uma visão prática. São Paulo: Metha, 2007.

PANERO, Julius; ZELNIK, Martin. Dimensionamento humano para espaços interiores. Barcelona: G. Gili, 2002.

PIRES, Dorotéia Baduy. O desenvolvimento de produtos de moda: uma atividade multidisciplinar. In: CONGRESSO BRASILEIRO DE PESQUISA E DESENVOLVIMENTO EM DESIGN, P\&D DESIGN, 6, 2004. São Paulo. Anais... São Paulo: 2004. 1 CD-ROM.

RADICETTI, Elaine. A ergonomia da roupa para o cliente do Novo Milênio. In: CONGRESSO NACIONAL DE TÉCNICOS TÊXTEIS, 6., 2004, Fortalieza. Anais... Fortaleza: ABTT, 2004.

RECH, Sandra Regina. Moda: por um fio de qualidade. Florianópolis: Udesc, 2002.

SILVEIRA, Icléia. Usabilidade do vestuário: fatores técnicos/funcionais. Modaplavra ePeríodico, Florianópolis, Ano 1, n.1, p. 21-39, jan./jul. 2008.

. Análise da Implantação do sistema CAD na indústria do vestuário. In: Moda palavra. Florianópolis: UDESC/CEART, 2003. v.3, p. 17-30.

SOARES, Carmem. Imagens da educação no corpo. Campinas, São Paulo: Autores Associados, 2001.

SOUZA, Patrícia de Mello. A modelagem tridimensional como implemento do processo de desenvolvimento do produto de moda. Bauru, 2006. Dissertação (Mestrado em Desenho Industrial) - Universidade Estadual Paulista.

SOUZA, Walkiria Guedes de. Modelagem no design do vestuário. Disponível em <http://fido.palermo.edu/servicios_dyc/encuentro2007/02_auspicios_publicaciones/actas_ diseno/articulos_pdf/A6045.pdf >. Acesso em: 23 jul. 2010.

SPAINE. Patricia Aparecida de; MAFFEI, Simone Thereza Alexandrino. O conhecimento ergonômico nas fases de odelagem de underwear: Uma Contribuição In: CONGRESSO BRASILEIRO DE ERGONOMIA - ABERGO, 15., 2008, Porto Seguro, BA. Anais... Porto Seguro: ABERGO, 2008. p. 201 - 208.

SUONO, Celso Tetsuro. O desenho técnico do vestuário sob a ótica do profissional da área de modelagem. Bauru, 2007. 135 p. Dissertação (Mestrado em Desenho Industrial) Universidade Estadual Paulista. 
TREPTOW, Doris. Inventando moda: planejamento de coleção. Brusque: D. Treptow, 2003.

WEERDMEESTER, Bernard; DUL, Jan. Ergonomia Prática. São Paulo: Edgard Blücher, 2001.

WOLTZ, Silvia Argenton S.; WOLTZ, Ana Maria. A modelagem como fator determinante na transformação do projeto em produto de Moda. In: CONGRESSO BRASILEIRO DE PESQUISAS E DESENVOLVIMENTO EM DESIGN, 7., 2006, Curitiba. Anais... Curitiba: P\&D Design, 2006. 